\title{
Pengaruh waktu pemangkasan pucuk dan sisa buah setelah penjarangan terhadap hasil produksi tanaman semangka (Citrullus vulgaris schard)
}

\author{
(Effect of time shoots pruning and rest of fruit after treatment on the production plant \\ watermelon (Citrullus vulgaris schard))
}

\author{
A. D. Yuriani, E. Fuskhah, Yafizham \\ Agricultural Department, Faculty of Animal and Agricultural Sciences, Diponegoro University \\ Tembalang Campus, Semarang 50275 - Indonesia \\ Corresponding E-mail:anitayuriani@gmail.com
}

\begin{abstract}
The objective of this research was to know growth and the production of watermelon plants through the treatment of pruning time on shoots and the amount of residual fruit after thinning. The research was carried out on Klaten Watermelon Clay, located in Genukan Village, Wedi Sub-district, Klaten District, and at the Laboratory Chemistry and Food Nutrition Faculty of Animal and Agricultural Sciences, Diponegoro University from February to May 2017. The research was arranged using completely randomized factorial design with the first factor being shoot pruning time $\left(\mathrm{P} 1=\right.$ no trimming, $\mathrm{P} 2=3^{\text {rd }}$ week, P3 $=6^{\text {th }}$ week, $\mathrm{P} 4=3^{\text {rd }}$ and $6^{\text {th }}$ week) and the second factor was the rest of the fruit after thinning $(\mathrm{Q} 1=$ without thinning, $\mathrm{Q} 2$ = thinning leaves 1 piece, $\mathrm{Q} 3=$ thinning leaves 2 pieces $)$. The results showed the treatment of pruning of shoots and the remaining fruit after spacing did not affect the growth plant height and number of leaves watermelon until $8^{\text {th }}$ week. However pruning of shoots $3^{\text {rd }}$ week and $6^{\text {th }}$ week can affect fruit diameter, fresh fruit weight, and fruit sugar levels. Treatment of the remaining fruit after the spacing is pruned 2 pieces affect the diameter of fruit and fresh weight of fruit while the rest of the fruit after spacing is purned 1 pieces fruit affect the fruit sugar levels.
\end{abstract}

Keywords: watermelon, pruning, thinning, production

\begin{abstract}
ABSTRAK
Penelitian bertujuan untuk mengetahui pertumbuhan dan hasil produksi tanaman buah semangka melalui perlakuan waktu pemangkasan pada pucuk dan jumlah sisa buah setelah penjarangan. Penelitian ini dilaksanakan pada di lahan Sahabat Semangka Klaten, yang terletak di Desa Genukan, Kecamatan Wedi, Kabupaten Klaten, dan di Laboratorium Kimia dan Gizi Pangan Fakultas Peternakan dan Pertanian Universitas Diponegoro dari bulan Juli - September 2017. Penelitian disusun menggunakan rancangan acak lengkap factorial dengan faktor pertama adalah waktu pemangkasan pucuk $\left(\mathrm{P}_{1}=\right.$ tanpa pemangkasan, $\mathrm{P}_{2}=$ minggu ke $3, \mathrm{P}_{3}=$ minggu ke $6, \mathrm{P}_{4}=$ minggu ke 3 dan 6) dan faktor kedua adalah sisa buah setelah penjarangan $\left(\mathrm{Q}_{1}=\right.$ tanpa penjarangan, $\mathrm{Q}_{2}=$ penjarangan disisakan 1 buah, $\mathrm{Q}_{3}=$ penjarangan disisakan 2 buah). Hasil penelitian menunjukan perlakuan pemangkasan pucuk dan sisa buah setelah penjarangan tidak mempengaruhi pertumbuhan tinggi tanaman dan jumlah daun semangka sampai minggu ke 8. Namun pemangkasan pemangkasan pucuk minggu ke 3 dan 6 mempengaruhi diameter buah, bobot segar buah, dan kadar gula buah. Perlakuan sisa buah setelah penjarangan yang dijarangkan 2 buah mempengaruhi diameter buah dan bobot segar buah sedangkan sisa buah setelah penjarangan yang dijarangkan 1 buah mempengaruhi kadar gula buah.

Kata Kunci: semangka, pemangkasan, penjarangan, produksi
\end{abstract}




\section{PENDAHULUAN}

Semangka (Citrullus vulgari Schard) merupakan tanaman buah berasal dari Afrika dan saat ini telah menyebar ke seluruh negara, baik di daerah sub tropis maupun tropis seperti Afrika Selatan, Cina, Jepang, dan Indonesia. Buahbuahan memiliki potensi untuk dikembangkan dengan pertimbangan permintaanya terus meningkat. Semangka merupakan salah satu komoditas buah yang mempunyai prospek untuk dikembangkan. Tanaman semangka memiliki beberapa kenanekaragaman seperti semangka merah atau kuning dan semangka berbiji atau semangka non biji. Tanaman semangka merupakan tanaman yang bersifat semusim dan tergolong cepat berproduksi (Sunarjono, 2006). Panen semangka dilakukan pada umur yang relatif singkat (genjah) sekitar 50 - 75 hari (Rukmana,2006). Tanaman semangka termasuk salah satu buah yang digemari masyarakat Indonesia karena selain rasanya yang manis, juga renyah dan kandungan airnya yang banyak.

Semangka memiliki daya tarik bagi petani karena memiliki nilai ekonomisnya yang tinggi. Semangka termasuk salah satu jenis buah yang digemari namun budidaya semangka di Indonesia masih kurang atau terbatas sehingga belum mampu untuk memenuhi permintaan konsumen dalam negeri. Semangka dalam pasar dunia memiliki permintaan mencapai 1.506 .000 ton dan sampai saat ini Indonesia belum dapat mengekspor semangka karena produksi masih rendah untuk memenuhi permintaan dalam negeri yang terus meningkat. Tingkat konsumsi buahbuahan setiap tahunnya semakin meningkat seiring dengan peningkatan jumlah penduduk dan pola makan masyarakat yang mulai menyukai buah-buahan termasuk semangka. Menurut Badan Pusat Statistik (2012) produksi tanaman semangka pada tahun 2008 hingga 2012 adalah sebagai berikut $371.498,474.327,348.631,497.650$ dan 520.891 ton. Produksi semangka yang terus meningkat upaya yang terus dilakukan antara lain melalui perluasan areal tanam dan peningkatan hasil semangka.

Tanaman semangka tanpa biji lebih banyak digemari oleh masyarakat dibandingkan semangka berbiji, karena selain rasanya yang manis juga mempunyai prospek ekonomi yang tinggi dibandingkan tanaman semangka berbiji namun karena kurangnya budidaya semangka tanpa biji kebutuhan pasar dalam negeri belum dapat tercukupi. Beberapa faktor yang mempengaruhi yaitu teknik budidaya yang kurang tepat. Upaya yang dapat dilakukan untuk meningkatkan produksi semangka salah satunya dengan melakukan pemangkasan dan penjarangan buah. Pemangkasan merupakan salah satu cara alternatif yang dapat dilakukan agar semangka dapat tumbuh dengan optimal sehingga dapat menghasilkan kualitas buah yang baik. Pemangkasan dalam tanaman buah sendiri bertujuan untuk mengoptimalkan proses produksi dan mengurangi resiko terjadinya serangan hama dan penyakit tanaman, serta merangsang tumbuhnya tunas-tunas produktif. Penjarangan buah merupakan kegiatan yang dilakukan untuk mengurangi jumlah buah yang terdapat dalam setiap pohon sehingga dapat menghasilkan buah yang memiiki ukuran yang lebih besar.

Pemangkasan merupakan salah satu cara yang dapat dilakukan untuk meningkatkan kualitas buah agar hasil produksi maksimal pada setiap tanaman. Pemangkasan sendiri merupakan suatu tindakan umum yang dilakukan pada tanaman holtikultura yang bertujuan untuk mendapatkan kualitas dan kuantitas serta poduksi yang tinggi. Pemangkasan yang dilakukan pada tanaman semangka adalah pemangkasan pucuk cabang. Pemangkasan pucuk cabang akan memberi pengaruh berbeda terhadap tingkat perkembangan tanaman dan dapat meningkatkan kualitas serta produksi semangka (Rukmana, 1995). Pemangkasan dapat dilakukan dengan cara memotong ujung atau pucuk tanaman yang disebut pemangkasan pucuk. Pemangkasan pucuk utama memiliki manfaat antara lain untuk mengurangi persaingan hasil dari fotosintesis di antara daun dengan buah, mengurangi terjadinya persaingan unsur hara, mengurangi terjadinya persebaran hama dan penyakit tanaman dengan cepat, dan dapat meningkatkan ukuran serta bobot buah. Keadaan ini akan mengurangi kelembaban di sekitar tanaman dan dapat mengurangi resiko terserangnya hama dan penyakit pada semangka (Mangal et al., 1981).

Penjarangan dilakukan agar tidak terjadi persaingan unsur hara dalam proses pembentukan bakal calon buah dalam satu tanaman agar dapat 
menghasilkan buah yang lebih seragam. Penjarangan buah pada tanaman semangka akan mengurangi persaingan buah dalam mendapatkan asimilat, buah akan berkebang lebih optimal sehingga menghasilkan buah yang lebih besar dan lebih seragam (Santoso, 1993). Penjarangan buah sendiri bertujuan untuk menghasilkan buah bermutu, memiliki ukuran yang seragam, menjamin kontinuitas produksi dan mengurangi resiko kerusakan atau kematian tanaman. Tanaman semangka dalam satu pohon sebaiknya hanya dipelihara maksimal 2 buah. Buah yang dipertahankan adalah buah yang memiliki pertumbuhan baik. Buah yang baik tampak dari penampilan fisiknya, yaitu ukurannya lebih besar dari lainnya, tidak cacat, dan bentuknya tidak memanjang (Duljapar dan Setyowati, 2000).

Tujuan dari penjarangan buah yaitu untuk menghasilkan buah bermutu, memiliki ukuran yang seragam, memperpanjang masa berbuah, menjamin kontinuitas produksi dan mengurangi resiko kerusakan atau kematian tanaman serta memperpanjang umur produktif tanaman.

\section{MATERI DAN METODE}

Penelitian ini dilaksanakan pada bulan Juli September 2017 di lahan "Sahabat Semangka Klaten", yang terletak di Desa Genukan, Kecamatan Wedi, Kabupaten Klaten, Provinsi Jawa Tengah.

\section{Materi Penelitian}

Bahan yang digunakan dalam penelitian ini adalah benih semangka hibrida wishmeluck, media tanam berupa tanah, pupuk kandang, pupuk NPK. Alat yang digunakan adalah, nampah kayu, polybag kecil, cangkul, sekop, mulsa plastik, gunting, meteran, timbangan, Refractometer Brix, bambu penanda, kertas label, alat tulis dan kamera.

\section{Metode Penelitian}

Rancangan penelitian dan Analisis Data

Rancangan yang digunakan adalah Rancangan Acak Lengkap (RAL) pola faktorial 4 x 3 dengan tiga ulangan. Faktor pertama adalah waktu pemangkasan pucuk yang terdiri dari 3 tingkat $\left(\mathrm{P}_{1}=\right.$ tanpa pemangkasan, $\mathrm{P}_{2}=$ minggu ke
$3, \mathrm{P}_{3}=$ minggu ke $6, \mathrm{P}_{4}=$ minggu ke 3 dan 6 ). Faktor kedua adalah sisa buah setelah penjarangan jumlah buah $\left(\mathrm{Q}_{1}=\right.$ tanpa penjarangan, $\mathrm{Q}_{2}=1$ buah, $\mathrm{Q}_{3}=2$ buah). Data hasil pengamatan dianalisis keragamannya dan dilanjutkan dengan uji jarak berganda Duncan dengan taraf 5\%.

\section{Prosedur Penelitian}

Prosedur penelitian yang dilakukan pada tahap awal yaitu persemaian. Persemaian dilakukan dengan cara merendam benih semangka dengan air cucian beras selama 1 malam, setelah direndam benih dipindah pada polybag kecil untuk melakukan persemaian dengan media tanam pupuk kandang. Setelah disemai benih ditutupi dengan plastik transparan agar tidak terserang hama dan rusak karena terkena angin. Persemaian dilakukan selama 7 - 10 hari sampai bibit memiliki 2 - 3 helai daun.

Pengolahan lahan, pengolahan lahan dilakukan bersamaan dengan proses penyemaian. Pengolahan lahan pertama yang dilakukan yaitu dengan membersihkan sisa-sisa tanaman yang masih ada pada lahan seperti sisa-sisa perakaran, bebatuan dan sampah yang ada pada lahan. Pengolahan lahan kedua yaitu pembuatan bedengan dengan ukuran $6 \times 3 \mathrm{~m}$ sebanyak 36 petak unit percobaan kemudian petak ditutup dengan mulsa dan dibuat lubang tanam, jarak antar tanaman yaitu $75 \mathrm{~cm}$. Setiap petak unit percobaan terdiri dari 8 tanaman semangka. Pemberian pupuk kandang dilakukan pada awal sebelum penanaman. Pemberian pupuk kandang dilakukan dengan dosis 4 ton/ha setelah itu didiamkan selama satu minggu.

Penanaman bibit semangka dilakukan pada pagi hari, setiap satu lubang tanam ditanami satu bibit semangka. Penanaman dilakukan dengan bibit yang sudah memiliki panjang akar kurang lebih $3 \mathrm{~cm}$. Bibit semangka ditanam pada kedalaman $1,5 \mathrm{~cm}$. Pemberian pupuk dilakukan pada 10, 15, 30, 45 hari setelah tanam (HST), Pemupukan dilakukan dengan cara diletakkan di sekeliling lubang tanam.

Pemeliharaan meliputi penyulaman, pengairan, penyiangan gulma, pengendalian hama dan penyakit tanaman. Penyulaman tanaman dilakukan pada tamanan saat berumur 7 hari. Penyulaman dilakukan dengan cara mengganti bibit tanaman yang rusak atau bibit yang 
pertumbuhannya lambat atau kurang baik dengan mengganti tanaman tersebut dengan tanaman baru yang lebih sehat. Pengairan dilakukan dengan menggunakan sistem Farrow Irrigation yaitu air dialirkan melalui saluran diantara bedengan, frekuensi pemberian air pada musim kemarau 4 6 hari dengan volume pengairan tidak berlebihan apabila dengan pompa air sumur (diesel air) penyiraman dilakukan dengan bantuan slang plastik yang cukup besar sehingga lebih cepat. Penyiangan gulma dilakukan dengan cara mencabut semua gulma yang tumbuh disekitar tanaman semangka sehingga tidak menggaggu proses pertumbuhan tanaman semangka itu sendiri. Pengendalian hama dan penyakit tanaman, hama dan penyakit tanaman yang terdapat pada tanaman semangka adalah Aphids dan Trhips yang mengakibatkan tanaman menjadi kerdil dan keriting pada daun semangka. Tanaman yang terkena hama dan penyakit kerdil tidak tumbuh dengan baik tanaman tersebut tidak akan bertambah panjang dan daunnya akan menggulung atau keriting dan tanaman tersebut tidak akan bisa menghasilkan bunga untuk dipolinasikan pada bunga jantan. Pengendalian hama dan penyakit tanaman ini bisa dilakukan dengan cara mencabut tanaman tersebut agar tidak menular pada tanaman yang lain atau dapat dikendalikan dengan penyemprotan samite dengan dosis $0,5 \mathrm{ml}$ pada tanaman yang terserang .

Pemangkasan dilakukan sesuai waktu yang ditentukan. Pemangkasan dilakukan pada usia tanaman 3 minggu, pemangkasan pada usia tanaman 6 minggu, pemangkasan pada usia 3 dan 6 minggu serta tidak dilakukan pemangkasan. Pemangkasan dilakukan dengan cara memangkas pucuk tanaman dan sulur yang terdapat pada tanaman semangka. Penjarangan dilakukan pada tanaman berumur 40 - 45 hari, penjarangan dilakukan dengan menyisakan beberapa buah pada tanaman. Penjarangan dilakukan dengan cara menyisakan bakal buah yang memiliki penampilan baik pada setiap tanaman. Penjarangan dilakukan dengan menyisakan 1 buah atau disisakan 2 buah pada setiap bedeng dengan faktor yang ditentukan.

Panen dan pasca panen, pemanenan semangka dilakukan pada saat umur semangka 60 hari tanam dengan cara memotong buah semangka yang sudah layak dan sudah kelihatan matang. Semangka yang sudah layak untuk dipanen memiliki ciri-ciri : perubahan warna pada buah, dan batang buah mulai mengecil maka buah tersebut dapat dipanen. Pemanenan buah dilakukan pada saat cuaca cerah dan tidak berawan sehingga buah dalam kondisi kering permukaan kulitnya dan dapat bertahan selama masa penyimpanan. Buah yang sudah dipanen akan di timbang untuk mengetahui bobot segar buah, selain di timbang buah akan diukur diameternya. Setelah itu untuk mengetahui kadar gula pada setiap buah dilakukan pengukuran dengan menggunakan alat Refractometer Brix.

\section{HASIL DAN PEMBAHASAN}

Hasil analisis ragam menunjukkan bahwa tidak terdapat interaksi perlakuan pemangkasan pucuk dan sisa buah setelah penjarangan terhadap panjang tanaman. Pemangkasan pucuk dan sisa buah setelah penjarangan tidak berpengaruh nyata pada panjang tanaman. Pemangkasan pucuk dan sisa buah setelah penjarangan terhadap panjang tanaman disajikan pada Tabel 1 .

Hasil analisis ragam menunjukan bahwa

Tabel 1. Panjang Tanaman Akibat Perlakuan Pemangkasan Pucuk dan Sisa Buah Setelah Penjarangan

\begin{tabular}{cccccc}
\hline \hline & \multicolumn{5}{c}{ Pemangkasan Pucuk } \\
\cline { 2 - 6 } $\begin{array}{c}\text { Perlakuan } \\
\text { Penjarangan }\end{array}$ & P1 (Kontrol) & $\begin{array}{c}\text { P2 } \\
\text { (Minggu ke } \\
\text { 3 ) }\end{array}$ & $\begin{array}{c}\text { P3 (Minggu } \\
\text { ke 6) }\end{array}$ & $\begin{array}{c}\text { P4 (Minggu } \\
\text { ke 3 dan 6) }\end{array}$ & $\begin{array}{c}\text { Rata- } \\
\text { rata }\end{array}$ \\
\hline & \multicolumn{7}{c}{ Q1 (Kontrol) } & 321,33 & 298,67 & 282,50 & 361,67 & 316,04 \\
Q2 (1 buah) & 360,50 & 342,33 & 313,33 & 317,33 & 333,38 \\
Q3 (2 buah) & 302,50 & 314,00 & 313,00 & 299,50 & 307,25 \\
Rata-rata & 328,11 & 318,33 & 302,94 & 326,16 & \\
\hline
\end{tabular}


tidak terdapat interaksi antara perlakuan pemangkasan pucuk dan sisa buah setelah penjarangan terhadap panjang tanaman. Hal ini dikarenakan hasil fotosintat lebih di distribusikan pada proses panjang tanaman. Pemangkasan pucuk dan sisa buah setelah penjarangan tidak menunjukan perbedaan yang nyata terhadap tinggi tanaman, hal ini diduga karena dilakukannya pemangkasan pucuk membuat hasil fotosintat akan didistribusikan ke banyak cabang. Gardner et.al (1991) menyatakan bahwa hasil fotosintat akan didistribusikan ke meristem ujung untuk menghasilkan sel-sel baru diujung batang yang mengakibatkan tumbuhan bertambah tinggi. Pertumbuhan tanaman yang cepat menyebabkan struktur organ vegetatif tanaman juga cepat terbentuk yang dibantu oleh beberpa faktor lingkungan antara lain seperti suhu, cahaya dan dibutuhkan dalam pertambahan panjang batang tanaman dan daun Soeb (2002). Faktor lain yang mendukung adalah penyinaran matahari yang sama pada semua perlakuan menyebabkan panjang tanaman yang tidak berbeda nyata. Immawati et al. (2013) menyatakan bahwa panjang tanaman dikendalikan oleh faktor genetik, selain itu dipengaruhi juga oleh faktor lingkungan.

\section{Jumlah daun (JD)}

Hasil analisis ragam menunjukkan bahwa tidak terdapat interaksi perlakuan pemangkasan pucuk dan sisa buah setelah penjarangan terhadap jumlah daun. Perlakuan pemangkasan pucuk dan sisa buah setelah penjarangan tidak berpengaruh nyata pada jumlah daun. Pemangkasan pucuk dan sisa buah setelah penjarangan terhadap jumlah daun disajikan pada Tabel 2.

Tabel 2. Jumlah Daun Akibat Perlakuan Pemangkasan Pucuk dan Sisa Buah Setelah Penjarangan

\begin{tabular}{lccccc}
\hline \hline \multirow{2}{*}{$\begin{array}{c}\text { Perlakuan } \\
\text { Penjarangan }\end{array}$} & P1 (Kontrol) & $\begin{array}{c}\text { P2 (Minggu } \\
\text { ke 3) }\end{array}$ & $\begin{array}{c}\text { P3 } \\
\text { (Minggu } \\
\text { ke 6) }\end{array}$ & $\begin{array}{c}\text { P4 } \\
\text { (Minggu 3 } \\
\text { dan 6) }\end{array}$ & Rata-rata \\
\cline { 2 - 6 } Q1 (Kontrol) & 155,17 & 152,67 & 150,33 & 147,17 & 151,33 \\
Q2 (1 buah) & 175,17 & 161,17 & 154,00 & 132,17 & 155,33 \\
Q3 (2 buah) & 146,50 & 150,83 & 127,33 & 139,83 & 141,13 \\
$\quad$ Rata-rata & 158,94 & 154,89 & 143,89 & 139,72 & \\
\hline
\end{tabular}

kelembapan. Isbandi (1983) menambahkan bahwa faktor lingkungan seperti kadar air, udara, dan unsur hara dari tanah turut mempengaruhi proses pertumbuhan tanaman termasuk asimilasi, pembentukan protoplasma baruserta meningkatkan dalam ukuran dan panjang tanaman.

Pemangkasan dan penjarangan merupakan upaya menciptakan keadaan tanaman menjadi lebih baik sehingga sinar matahari dapat masuk ke seluruh bagian tanaman, meningkatnya intersepsi cahaya yang masuk kebagian atas tanaman serta sirkulasi udara dan dan ketersediaan $\mathrm{CO}_{2}$ yang cukup serta faktor lain yang mendukung akan meningkatkan laju fotosintesis yang akhirnya meningkatkan ketersediaan fotosintat yang
Hasil tabel analisis ragam menunjukan bahwa pada tidak terdapat interaksi antara perlakuan pemangkasan pucuk dan sisa buah setelah penjarangan terhadap jumlah daun. Hal ini dikarenakan hasil fotosintat lebih di distribusikan pada proses penambahan jumlah daun. Pemangkasan pucuk dan sisa buah setelah penjarangan tidak menunjukan perbedaan yang nyata terhadap jumlah daun, hal ini diduga karena pada perlakuan tanpa pemangkasan tanaman akan terus tumbuh karena pertumbuhannya tidak dihambat akibat pemangkasan, sehingga dapat dihasilkan jumlah daun terbanyak dibandingkan dengan perlakuan lain yaitu dengan pemangkasan. Hasil yang sama terdapat pada penelitian Susiani (2003) yang menjelaskan bahwa perlakuan tanpa 
pemangkasan menghasilkan panjang tanaman dan jumlah daun lebih tinggi dibandingkan dengan perlakuan pemangkasan pada tanaman semangka.

Daun memiliki klorofil yang berperan dalam melakukan proses fotosintesis. Semakin banyak jumlah daun, maka tempat untuk melakukan proses fotosintesis menjadi lebih banyak. Hal tersebut dapat dikaitkan dengan sifat-sifat penyediaan unsur hara pada tanaman. Pada penjarangan pertumbuhan jumlah daun antar perlakuan sama. Hal ini sesuai dengan pendapat Gardner et al. (1991) yang menyatakan bahwa salah satu bagian yang pada masa pertumbuhan vegatatif semangka adalah daun muda atau tunas yang sedang tumbuh apabila kandungan klorofil cukup tinggi pada tanaman, maka akan diikuti dengan laju fotosintesis yang tinggi sehingga asimilat yang dihasilkan juga banyak. Asimilat adalah energi, dan sebagian energi yang berasal dari asimilat tersebut akan digunakan untuk energi pertumbuhan seperti dalam pembentukan jumlah daun, perkembangan luas daun ataupun organ tanaman yang lain Alam at al. (2010).

\section{Diameter buah (DB)}

Hasil analisis ragam menunjukkan bahwa terdapat interaksi perlakuan pemangkasan pucuk dan sisa buah setelah penjarangan terhadap jumlah daun. Perlakuan pemangkasan pucuk berpengaruh nyata pada jumlah daun serta berpengaruh nyata pada perlakuan sisa buah setelah penjarangan pada jumlah daun. Pemangkasan pucuk dan sisa buah setelah penjarangan terhadap jumlah daun disajikan pada Tabel 3 .
Hasil tabel analisis ragam menunjukan bahwa terdapat interaksi antara perlakuan pemangkasan pucuk dan penjarangan sisa buah. Hal ini dikarenakan proses penyerapan hasil fotosintat dan kebutuhan sinar matahari serta penyerapan unsur hara lebih difokuskan dalam pembentukan buah yang diserap secara maksimal oleh buah. Wartapa et al. (2009) menyatakan bahwa cabang tanaman yang sedikit menyebabkan fotosintat yang terbentuk sepenuhnya dapat disimpan pada buah dan menyebabkan diameter buah menjadi lebih besar. Untuk perlakuan pemangkasan pucuk dengan perlakuan tanpa pemangkasan dan tanpa penjarangan bebeda nyata dengan perlakuan penjarangan buah yang disisakan satu dan buah setiap tanamannya. Perlakuan pemangkasan pucuk minggu ke 3 dengan perlakuan tanpa penjarangan pucuk berbeda nyata dengan perlakuan penjarangan buah yang disisakan satu dan dua buah setiap tanamannya. Perlakuan pemangkasan pucuk minggu ke 6 dengan perlakuan tanpa penjarangan berbeda nyata dengan penjarangan buah yang disisakan satu buah dan dua buah setiap tanamannya. Perlakuan pemangkasan pucuk minggu ke 3 dan 6 dengan perlakuan tanpa penjarangan berbeda nyata dengan penjarangan satu buah dan penjarangan dua buah pada setiap tanamanya. Forth (1998) menyatakan bahwa produk fotosintesis yang berupa karbohidrat membentuk asam amino mengakibatkan terjadinya pertumbuhan pada tanaman, pertumbuhan tersebut berupa pembesaran sel dan pembelahan sel yang menjadikan diameter buah

Tabel 3. Diameter Buah Akibat Perlakuan Pemangkasan Pucuk dan Sisa Buah Setelah Penjarangan

\begin{tabular}{|c|c|c|c|c|c|}
\hline \multirow[b]{2}{*}{$\begin{array}{c}\text { Perlakuan } \\
\text { Penjarangan }\end{array}$} & \multicolumn{5}{|c|}{ Pemangkasan Pucuk } \\
\hline & P1 (Kontrol) & $\begin{array}{c}\text { P2 } \\
\text { (Minggu ke } \\
3 \text { ) }\end{array}$ & $\begin{array}{c}\text { P3 (Minggu } \\
\text { ke 6) }\end{array}$ & $\begin{array}{c}\mathrm{P} 4 \\
\text { (Minggu } 3 \\
\text { dan 6) } \\
\end{array}$ & Rata-rata \\
\hline & ----------- & ------ ( $\mathrm{cm})$ & --------------- & --------- & \\
\hline Q1 (Kontrol) & $8,70^{\mathrm{d}}$ & $11,71^{\mathrm{c}}$ & $10,16^{\mathrm{c}}$ & $16,81^{\mathrm{b}}$ & $11,84^{\mathrm{b}}$ \\
\hline Q2 (1 buah) & $18,36^{\mathrm{ab}}$ & $18,94^{\mathrm{ab}}$ & $17,88^{a b}$ & $19,32^{\mathrm{a}}$ & $18,63^{\mathrm{a}}$ \\
\hline Q3 (2 buah) & $18,58^{a b}$ & $18,62^{a b}$ & $18,37^{\text {ab }}$ & $19,55^{\mathrm{a}}$ & $18,78^{\mathrm{a}}$ \\
\hline Rata-rata & $15,21^{\mathrm{b}}$ & $16,42^{\mathrm{b}}$ & $15,47^{\mathrm{b}}$ & $18,56^{\mathrm{a}}$ & \\
\hline
\end{tabular}

Superskrip yang berbeda pada kolom atau baris rata-rata atau matrik interaksi menunjukkan berbeda nyata $(\mathrm{p}<0,05)$. 
bertambah. Hal tersebut diperkuat oleh pendapat Palmarum (1991) yang menyatakan bahwa ukuran buah ditentukan oleh dari banyaknya fotosintat yang dihasilkan.

Proses pembentukan buah persaingan perebutan unsur hara tidak terlalu banyak saingan sehingga penyerapan unsur hara untuk tanaman itu sendiri akan terpenuhi dan buah yang dihasilkan memiliki diameter buah yang tinggi. Gumelar et al. (2014) menyatakan bahwa pengurangan buah dapat meningkatkan diameter buah hal tersebut bertujuan untuk mengurangi persaingan penggunaan fotosintat antara buah dan bunga, sehingga fotosintat dapat terkonsentrasi untuk perkembangan buah. Prajnata (2000) menyatakan bahwa salah satu tujuan dilakukan penjarangan buah yaitu untuk memperoleh ukuran dan bentuk buah yang seragam dan besar.

\section{Bobot Segar Buah (BSB)}

Hasil analisis ragam menunjukkan bahwa tidak terdapat interaksi perlakuan pemangkasan pucuk dan sisa buah setelah penjarangan terhadap bobot segar buah. Perlakuan pemangkasan pucuk dan sisa buah setelah penjarangan berpengaruh nyata pada bobot segar buah serta berpengaruh nyata. Pemangkasan pucuk dan sisa buah setelah penjarangan terhadap jumlah daun disajikan pada Tabel 4.

Hasil tabel analisis ragam menunjukan bahwa pada perlakuan pemangkasan pucuk berpengaruh nyata pada bobot segar buah. Hal ini diduga karena tidak terjadi persaingan nutrisi dan penyerapan sinar matahari sehingga kandungan nutrisi dan sinar matahari yang dibutuhkan oleh tanaman dapat diserap oleh tanaman secara maksimal dan lebih di fokuskan pada buah sehingga dapat meningkatkan bobot segar buah. Hilangnya sebagian daun setelah dilakukan pemangkasan dapat dipulihkan dengan cepat karena tanaman masih dalam fase vegetatif dan pembentukan daun masih giat dilakukan, sehingga proses fotosintesis dapat berjalan dengan lancar kembali dan pertumbuhan dapat meningkat, yang mengakibatkan bobot buah menjadi meningkat. Hal ini sesuai dengan pendapat Sumiati (1987) yang menyatakan bahwa pemangkasan yang dilakukan pada tanaman semangka dengan meninggalkan tiga cabang utama dapat meningkatkan bobot per buah dan bobot buah per tanaman. Semakin banyak hasil fotosintesis maka cadangan makanan semakin banyak pula dan dapat digunakan untuk menigkatkan berat buah. Cit Majid (2012).

Sisa buah setelah penjarangan berpengaruh nyata pada bobot segar buah. Hal ini dikarenakan penjarangan dua buah pertanaman semua unsur hara dan hasil fotosintat terpusat untuk pembentukan buah, sehingga bobot dan kualitas buah yang terbentuk lebih baik dan seragam. Pada proses pembentukan buah persaingan perebutan unsur hara tidak terlalu banyak saingan sehingga penyerapan unsur hara untuk tanaman itu sendiri akan terpenuhi dan buah yang dihasilkan memiliki bobot yang tinggi. Zamzami et al. (2015) menyatakan bahwa semakin sedikit buah yang dijarangkan pada satu tanaman maka semakin besar volume buah dan bobot buah persatuan

Tabel 4. Bobot Segar Buah Akibat Perlakuan Pemangkasan Pucuk dan Sisa Buah Setelah Penjarangan.

\begin{tabular}{|c|c|c|c|c|c|}
\hline \multirow[b]{2}{*}{$\begin{array}{c}\text { Perlakuan } \\
\text { Penjarangan }\end{array}$} & \multicolumn{5}{|c|}{ Pemangkasan Pucuk } \\
\hline & P1 (Kontrol) & $\begin{array}{c}\mathrm{P} 2 \\
\text { (Minggu ke } \\
\text { 3) }\end{array}$ & $\begin{array}{c}\text { P3 (Minggu } \\
\text { ke 6) }\end{array}$ & $\begin{array}{c}\mathrm{P} 4 \\
\text { (Minggu 3 } \\
\text { dan 6) }\end{array}$ & Rata-rata \\
\hline O1 (Kontrol) & 225 & 271 & kg ) -----.- & 338 & $267^{\mathrm{b}}$ \\
\hline Q2 (1 buah) & 3,60 & 3,90 & 3,17 & 4,13 & $3,70^{\mathrm{a}}$ \\
\hline Q3 (2 buah) & 3,75 & 4,24 & 3,58 & 4,66 & $4,05^{\mathrm{a}}$ \\
\hline Rata-rata & $3,20^{\mathrm{bc}}$ & $3,61^{\mathrm{ab}}$ & $3,03^{\mathrm{c}}$ & $4,06^{\mathrm{a}}$ & \\
\hline
\end{tabular}

Superskrip yang berbeda pada kolom atau baris rata-rata menunjukkan berbeda nyata $(\mathrm{p}<0,05)$. 
buah, hal ini disebabkan fotosintat yang dihasilkan oleh daun hanya terkonsentrasi kepada buah yang tidak terlalu banyak, sehingga bobot satuan buah akan meningkat.

\section{Kadar Gula Buah (KGB)}

Hasil analisis ragam menunjukkan bahwa tidak terdapat interaksi perlakuan pemangkasan pucuk dan sisa buah setelah penjarangan terhadap kadar gula buah. Perlakuan pemangkasan pucuk berpengaruh nyata pada kadar gula buah serta tidak berpengaruh nyata pada perlakuan sisa buah setelah penjarangan pada kadar gula buah. Pemangkasan pucuk dan sisa buah setelah penjarangan terhadap jumlah daun disajikan pada Tabel 5 . menyatakan bahwa tanaman semangka yang kekurangan sinar matahari selama masa pertumbuhannya akan menurunkan kualitas rasa manis pada buahnya. Tanaman semangka yang tidak dipangkas akan berwarna pucat karena ternaungi oleh daun-daun yang tumbuh rimbun dan cenderung menghasilkan buah yang kurang manis, sedangkan tanaman yang diberi perlakuan pemangkasan memiliki warna cerah dan kadar gula yang manis. Hal ini sesuai dengan pendapat Rambe et al. (2012) menyatakan bahwa perlakuan pemangkasan dapat memperbaiki penampilan buah terutama terhadap warna dan kadar gula.

Sisa buah setelah penjarangan tidak berpengaruh nyata pada kadar gula buah. Penjarangan sisa buah tertinggi adalah

Tabel 5. Kadar Gula Buah Akibat Perlakuan Pemangkasan Pucuk dan Sisa Buah Setelah Penjarangan

\begin{tabular}{lccccc}
\hline \hline & \multicolumn{5}{c}{ Pemangkasan Pucuk } \\
\cline { 2 - 5 } $\begin{array}{c}\text { Perlakuan } \\
\text { Penjarangan }\end{array}$ & P1 (Kontrol) & $\begin{array}{c}\text { P2 } \\
\text { (Minggu ke }\end{array}$ & $\begin{array}{c}\text { P3 (Minggu } \\
\text { ke 6) }\end{array}$ & $\begin{array}{c}\text { P4 (Minggu } \\
\text { 3 dan 6) }\end{array}$ & Rata-rata \\
\hline & & 3) & & \\
\hline Q1 (Kontrol) & 6,02 & 6,93 & 6,92 & 7,76 & 6,83 \\
Q2 (1 buah) & 7,12 & 6,47 & 8,27 & 7,42 & 7,31 \\
Q3 (2 buah) & 7,02 & 7,37 & 7,05 & 7,70 & 7,28 \\
$\quad$ Rata-rata & $6,67^{\mathrm{c}}$ & $6,92^{\mathrm{bc}}$ & $7,41^{\mathrm{ab}}$ & $7,62^{\mathrm{a}}$ & \\
\hline
\end{tabular}

Superskrip yang berbeda pada baris rata-rata menunjukkan berbeda nyata $(\mathrm{p}<0,05)$

Hasil tabel analisis ragam menunjukan bahwa pada perlakuan pemangkasan pucuk berpengaruh nyata pada kadar gula buah semangka. Hal ini diduga karena tidak terjadi persaingan nutrisi dan sinar matahari sehingga kandungan nutrisi dan sinar matahari yang dibutuhkan oleh tanaman dapat diserap oleh tanaman secara maksimal dan lebih di fokuskan pada buah sehingga dapat meningkatkan kadar gula pada setiap buah. Tanaman semangka memerlukan penyinaran matahari penuh sepanjang hari sekitar 10 hingga 12 jam. Hal ini sesuai dengan pernyataan Sumarna dan Kusnandi (1994) yang menyatakan bahwa sinar matahari penuh dengan kelembaban yang relatif rendah dapat memacu dan memperkuat pertumbuhan tanaman, meningkatkan kadar gula buah. Hal ini diperkuat dengan pendapat Duljapar (2000) yang penjarangan yang disisakan satu buah, hal ini diduga karena perlakuan satu buah per tanaman, source hanya mendistribusikan hasil fotosintesis untuk perkembangan satu buah, sedangkan pada perlakuan dua buah per tanaman source harus membagi hasil fotosintesis pada perkembangan dua buah. Pada perlakuan jumlah buah per tanaman melalui teknik penjarangan buah, source akan mentransportasikan hasil fotosintesis ke bagian sink yaitu buah sebagai sink utama. Kompetisi hasil fotosintesis antar buah akan rendah dengan adanya penjarangan buah Poerwanto (2003). Sehingga mengakibatkan tanaman dengan jumlah satu buah per tanaman akan lebih maksimal perkembangannya. Hal ini diperkuat dengan pendapat Sari (2009) yang menyatakan bahwa perlakuan jumlah buah per tanaman, variabel kemanisan daging buah paling 
manis terdapat pada perlakuan satu buah per tanaman dibandingkan peralakuan dua dan tiga buah per tanaman.

\section{KESIMPULAN}

Bedasarkan penelitian yang telah dilakukan maka dapat disimpulkan bahwa pertumbuhan tanaman semangka yang dicerminkan dengan tinggi tanaman dan jumlah daun tidak dipengaruhi oleh pemangkasan pucuk dan sisa buah setelah penjarangan. Namun pemangkasan pucuk minggu ke 3 dan 6 mampu meningkatkan secara signifikan diameter buah, bobot segar buah, dan kadar gula buah. Sisa buah setelah penjarangan 1 dan 2 buah memberikan hasil diameter buah dan bobot segar buah yang lebih tinggi dibandingkan dengan tanpa penjarangan buah. Penjarangan buah tidak mempengaruhi pada kadar gula buah. Interaksi antara pemangkasan pucuk dan sisa buah setelah penjarangan hanya mempengaruhi diameter buah.

\section{DAFTAR PUSTAKA}

Alam, M. S., S. M. Imran., M. A. Sattar., M.R. Islam., dan M. M. A. Hossain. 2010. Effect of different organic and inorganic fertilizers on growth and (Colocasia esculenta) cv. sali kachu. J. Agrofor. Environ. 4 (2): 53-56.

Badan Pusat Statistik. 2012. Produksi buahanbuahan menurut provinsi di Indonesia. Badan Pusat Statistik. Jakarta.

Duljapar, K. dan R.N. Setyowati,. 2000. Petunjuk bertanam semangka sistem turus. Penebar Swadaya. Jakarta. Hal 80.

Forth, D. H. 1998. Fundamental of soil science. Universitas Gadjah Mada Press. Yogyakarta.

Gardner, F. P., R. B. Pearce., dan R. L. Mitchell. 1991. Fisiologi tanaman budidaya. Universitas Indonesia Press. Jakarta.

Gumelar, R. M. R., S. H. Sutjahjo., S. Marwiyah., dan A. Nindita. 2014. Karakterisasi dan respon pemangkasan terhadap produksi serta kualitas buah genotipe semangka lokal. Jurnal Hortikultura Indonesia. 5:7383.

Immawati, D. R., S. Purwanti., dan D. Prajitno. 2013. Pengaruh pemangkasan terhadap produksi melon. J. Vegetalika. Vol.2 (4) : 25-34.

Isbandi, D. 1983. Fisiologi tanaman. Jakarta. Erlangga.

Mangal, J., L. A. S. Sindhu., dan V. C. Pandey. 1981. Effect of Stacking and pruning on growth and yield of watermelon. J. Agric. Res. 15(2):122-129.

Majid, S. I. 2012. Pengaruh pemangkasan terhadap pertumbuhan dan hasil beberapa varietas melon. Penebar Swadaya. Jakarta.

Palmarum, N. 1991. Pengaruh pemangkasan pucuk tanaman pada proses pertumbuhan dan hasil produksi Melon. J. Holtikultura Vo. 1. No. 4.

Poerwanto, R. 2004. Standar prosedur operasional komoditas semangka. Direktorat budi daya tanaman buah. Jakarta. Hal. 1- 49.

Prajnanta, F. 2003. Agribisnis semangka non-biji. Penebar Swadaya. Jakarta. Hal. 1- 4.

Rambe, S. S. M., I. Calista., dan K. Dinata. 2012. Peningkatan produktivitas dan penampilan buah jeruk gerga (RGL) di Kabupaten Lebong Provinsi Bengkulu.

Rukmana, R. 2006. Budidaya semangka hibrida. Kanisius. Yogyakarta.

Santoso, H. B. 1993. Semangka. Kanisius, Yogyakarta.

Soeb, M. 2002. Pengaruh pemangkasan dan pemberian mulsa terhadap pertumbuhan dan produksi tanaman mentimun (Cucumis sativus L.). Skripsi Sarjana 
Fakultas Pertanian USU. Medan.

Sumiati, E. 1987. Pengaruh pemangkasan cabang terhadap hasil dan kualitas semangka. Buletin Penelitian Hortikultura. 15: 49.54.

Susiani. 2003. Pengaruh dosis pupuk NPK dan pemangkasan terhadap pertumbuhan dan hasil tanaman semangka. J. Hortikultura 15(02):21-26.

Wartapa, A., Y. Efendi., dan Sukadi. 2009.
Pengaturan jumlah cabang utama dan penjarangan buah terhadap hasil dan mutu melon. Jurnal Ilmu Pertanian, volume 5(2): 150-163.

Zamzami., M. Nawawi., dan N. Aini. 2015. Pengaruh jumlah tanaman per polibag dan pemangkasan terhadap pertumbuhan dan hasil tanaman mentimun Kyuri (Cucumis sativus L.). J. Produksi Tanaman. 3: 113 119. 